\title{
The Improved Polymerase Chain Reaction Method Applied for Sex Identification of Crested Ibis, Nipponianippon
}

\author{
Kyung A Kim ${ }^{1,2}$, Jae SeokCha ${ }^{1,3}$, So Young Park ${ }^{1,2}$, Kyung Min Kim, Hee Cheon Park ${ }^{1,2, *}$ \\ ${ }^{1}$ Department of Biology, College of Natural Sciences, Kyungpook National University, Daegu, 702-701, Republic of Korea \\ ${ }^{2}$ Institute of Ornithology, Ky ungpook National University, Daegu, 702-701, Korea \\ ${ }^{3}$ Museum of Natural History, Ky ungpook National University, Gunwi, 716-822, Republic of Korea \\ ${ }^{4}$ School of Applied Biosciences, College of A griculture and Life Science, Ky ungpook National University, Daegu, 702-701, Korea
}

\begin{abstract}
Given the necessity for increased conservation of endangered birds such as the Crested ibis, it is crucial to identify the gender of individuals from species with similar external morphologies among females (ZW) and males(ZZ) to establish a self-sustainable population for restoration of the species. Moreover, raising young chicks during the juvenile period based on sex determination encourages familiarity, which might increase mating success rates. Thus, this study was carried out to determine the sex of Crested ibis chicks using three primers designed to check their identity. A set of polymerase chain reaction(PCR) primers was used to amplify a 276 bp chro mo-he licase-DNA binding protein region(CHD) on the $\mathrm{Z}$ chro mosome in both sexes, whereas the other set was used to amplify a $169 \mathrm{bp}$ female-specific CHD sequence on the W chromosome. The sequences have been submitted to NCBI(GenBank Accession Number: AB620020, AB620021). This method will enable researchers to determine the gender of Crested ibis more simply and quickly.
\end{abstract}

Keywords Sexidentification, Crested Ibis, Nipponianippon, CHD, Molecular Sex Identity

\section{Introduction}

The Crested ibis, Nipponianippon, is protected as an endangered species by the International Union for Conservation and as a National Treasure in South Korea(No. 198)(1). It is a mediumsized bird that has a long bill and legs, and belongs to the family Threskiornithidae, order Ciconiformes(2). The population has historical ranges in Northeast Asian countries such as Korea, Japan, China, and Far Eastern Russia(3-7), but this range has drastically decreased since the 1930s due to detrimental human activities(8-10). After the last observation of this species in the wild in the early 1980s(11), artificial incubation of this species was conducted for the first time in South Korea(12).

For conservation of endangered birds such as the Crested ibis, it is crucial to identify the gender of individuals with similar external morphologies among males(ZZ) and females (ZW) to establish a self-sustainable population $(13,14)$. Moreover, raising young chicks during the juvenile period based on sex determination encourages familiarity, which might increase mating success rates(15). As a result, it is

* Corresponding author:

heecheon@knu.ac.kr(HeeCheon Park)

Published online at http://journal.sapub.org/als

Copyright (C 2012 Scientific \& Academic Publishing. All Rights Reserved sexes. Therefore, many approaches have been applied to imperative to develop an accurate and way to determine identify sexes currently(16). Compared with other sexidentification approaches, DNA based methods are very effectivebecause a large amount of samples can be tested simultaneously(17).

For these reasons, there have been a number of advanced studies regarding the molecu lar sexing method in this species. As such, although several studies have been conducted to identify the sex of Crestedibis(18-20), the results were unclear or the identification methods were difficult to follow(19). Thus, this study was conducted to design primers to identify the sex of Crestedibis by amplifying Z-specific and $\mathrm{W}$-specific fragments. In addition, due to the $100 \mathrm{bp}$ difference in the sizes of two PCR amplicons, the current method overcomes the difficult situation wherein two fragments are amplified but the size difference between them is too small to allow for sex identification, as in the case of PCR using the P2 and P8 primers. As such, an attempt was made herein to identify the sex of Crestedibis using a single PCR reaction.

\section{Materials and Methods}

\section{Sampling and DNA Extraction}

The Crested ibis in this study included a pair of parent 
Crested ibis(CI1: adult male, CI2: adult female) and their four chicks(CI3, CI4, CI5 and CI6, respectively), which are the first artificially incubated in South Korea. All birds were bred at the Upo Crested ibis Restoration Center in captivity. Tissue specimens were collected from the feathers of the parents and chicks. DNA was extracted from the tissues of the calamus tips using the DNeasy Blood \& Tissue Kit(Qiagen GmbH, Hilden, Germany).

\section{CHD-W and CHD-Z gene amplification of Crestedibis}

First, PCR of the extracted DNA was performed using the $\mathrm{P} 2$ and P8 primers(21). The amplified CHD gene of the Crestedibis was electrophoresed on a $3 \%$ agarose gel, subjected to gel extraction and purification, and then sequenced. Using this identified base sequence, primers for sex identification were designed.

The forward primer(pcil:5'TGCTGA CTTGTACTTTAT GTTG3') and reverse primer (pci3:5' GA GATGGA GTCAC TATCAGAT3'), for amplification of the CHD-Z gene of Crested ibis were designed with an expected size for the amplicon of $276 \mathrm{bp}$. The second forward primer(pci2:5'AT GTGGCGTGCCCCCCCTA3') was designed for specific amplification of the CHD-W gene with an expected amplicon size of $169 \mathrm{bp}$. As such, sex identification of Crested ibis was performed by PCR using the pcil/2/3 primers. For the PCR, 38 cycles of denaturation $\left(94^{\circ} \mathrm{C}\right.$ for $30 \mathrm{sec}$.), annealing $\left(57^{\circ} \mathrm{C}\right.$ for $\left.30 \mathrm{sec}.\right)$, and extension $\left(72^{\circ} \mathrm{C}\right.$ for $60 \mathrm{sec}$.) were performed with Ex Taq poly merase(TaKaRa, Shiga, Japan) in a DNA Thermal Cycler(TaKaRa TP650, Shiga, Japan). After PCR, the products, the set of pcil, pci2 and pci3 primers, and the other set of $\mathrm{P} 2$ and $\mathrm{P} 8$ primers, were electrophoresed on a $2 \%$ agarose gel.

\section{DNA se quencing and alignment}

The amplicons derived from the gel extraction were subjected to cycle sequencing (Applied Biosystems, ABI 3730xl, Foster City, CA, U.S.A.). The final nucleotide sequence data reported in th is paper will appear in theDDBJ/EMBL/Gen B ank nucleotide sequence database with the accession numbers AB620020, AB620021.

\section{Results and Discussion}

The PCR products from the male and female were amplified with the pci1, pci2, and pci3 primers.

The pcil and pci2 PCR products were amplified in both the male and female, and the expected size of the amplicon was $276 \mathrm{bp}$ (Figure 1A). In contrast, pcil and pci3, specif ically designed for the identification of sex, produced a product only in the female, and the expected size of the amplicon was $169 \mathrm{bp}$ (Figure 1B). The final nucleotide sequences were submitted toNCBI(GenBank Accession Number AB620020 and AB620021Sex identification thus involves discrimination of the number of frag ments present in the PCR reaction: 1 or 2 . Therefore, a one-band PCR product indicates a male, and a two-banded PCR product indicates a fe male.(Figure 2A).PCR was performed using the P2 and P8 primers(Griffiths et al. 1998) and the pci1, pci2 and pci3 primers, after which electrophoresis was performed under the same conditions. Photos of the electrophoresis and the results of the comparison can be seen in Figure 2A and B.

Electrophoresis of the amplified products generated using pcil, pci2 and pci3 primers from the adult male(CI1) displayed only a single band while those generated from the adult female(CI2) displayed two bands. Therefore, it was considered that $\mathrm{CI} 3$ with one band was male and those with two bands, CI4, CI5, and CI6, were female (Figure 2A).

\section{Figure legends}

A Forward primer (pcil) TGCTGACTTGTACTTTATGTTG

Crested bis CHD-Z TGCTGACTTGTACTTPATGTTGCTGTIGGTTPAGTTGGTGTGTTIGGAGGTTGTT TTGGGTTTGGMTPTTGCACTGGTTPTTTGTPTTGATPTTGGTPTTPTTCCCCCTTI TCTGAACACACGTTTTTGACAGGCTAGGTAGAACTTTACTTATGTTCGTTAATCATA TAGCTTTGAACTATTTATTCTCAAATTCCAGATCAGCTTTAATGGAaGTGAAGGGG GCGCAGTAGGAGCAGAAGATACTCTGGATCTGATAGTGACTCCATCTC

Reverse primer (pci3) TAGACTATCACTGAGGTAGAG

B Forward primer (pci2) ATGTGGCGTGCCCCCCCTA

Crested ibis CHD-W ATGTGGCGTGCCCCCCCTATTTTTGACAGGCTAGAAAACACATTAATAAAATGTTTIT AgTCACGTAGCTTTGAATTATTTAATCTGAAATTCCAGATCAGCTTTAATGGAGGT AAGGGAAACGCAGTAGGAGCAGAAGATATTCTGGATCTGATAGTGACTCCATCTC

Reverse primer (pci3) TAGACTATCACTGAGGTAGAG

Figure 1. Positions and sequences of primers, and CHD-Z(A) and CHD-W(B) gene sequences of Crested ibis in South Korea. The nucleotide sequence data were registered in the DDBJ/EMBL/GenBank nucleotide sequence database with the accession numbers AB620020 for CHD-Z and AB620021 for CHD-W
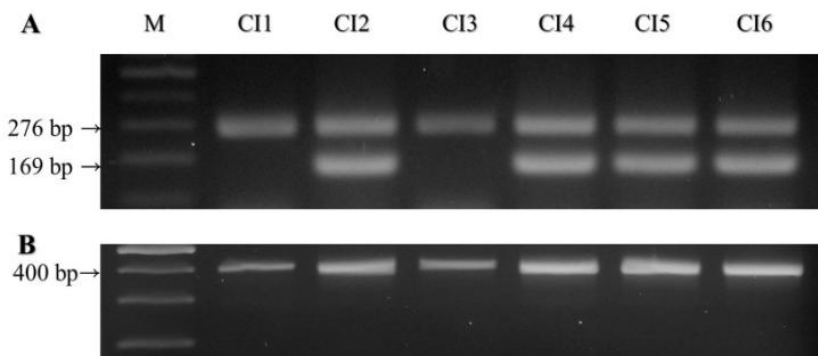

Figure 2. Identification of sex using $\mathrm{CHD}$ polymerase chain reaction(PCR) fragments amplified with the different primer sets(pci1, pci2, and pci3 primers(A) and $\mathrm{P} 2$ and $\mathrm{P} 8$ primers(B))of Crested ibis in South Korea. CI1 (adult male) was one band and CI2 (adult female) was two bands. Therefore, CI3 with one band was a male. On the other hand, CI4, C55, and CI6 showed the same two-banded pattern as the adult female(C2) and were thus female. The upper band size was $276 \mathrm{bp}$ and the lower band was $169 \mathrm{bp}$. However, C12(adult female) showed two bands that looked like one. The upper band size was about $400 \mathrm{bp}$ andthe lower band was about $380 \mathrm{bp}$. The products were separated under the same conditions as in figure $2 \mathrm{~A}$. Marker(M) is 100 bp DNA Ladder. CI1: adult male and CI2: adult female. CI3: first chick. CI4: second chick. CI5: third chick. CI6: fourth chick

\section{Conclusions}

Even when P2 and P8 primers were used in PCR for the identification of sex, which was previously the simplest method as indicated in previous studies, it was still difficult to separate the two electrophoretic bands, although the frag ments were amplified successfully. This could be attributed to the small difference between the sizes of the $\mathrm{Z}$ and $\mathrm{W}$-specific frag ments (22).

Thus, only when electrophoresis was performed in $3 \%$ agarose gel for a long time could the two bands be sepa- 
rated(19). In the case of the PCR products created using the pci1, pci2 and pci3 primers, however, separation of the two bands via electrophoresis was easy because the difference between the two bands was $107 \mathrm{bp}$, which is greater than that between the products created via PCR using the P2 and P8 primers. The set of pcil, pci2 and pci3 primers in our experiment has been thought to be very useful to determine the sex identification in Crested ibis. Therefore this study will promote a molecular genetic study on gender identification of the current Crested ibis.

\section{REFERENCES}

[1] IUCN(2009) in Wild life in a changing world - an analy sis of the 2008 iucn red list of threatened species, eds Vie J, Hilton-Tay lor C, Stuart S(Gland, Switzerland), pp 107

[2] The Howard and Moore complete checklist of the birds of the world, 3rd ed(2003), edsDickinson E-C(Princeton University Press, Princeton and Oxford, NJ).pp 82, 877

[3] Yasuda K(1983) Distribution of Crested Ibis as found in literature. In Nipponianippon,eds Yamashima Y, Nakanishi G(Newton Books, Tokyo)

[4] Yamashina Y(1975) The feed ing of Japanese Crested Ibis. In Endangered Birds, edsTemple S(University of Wisconsin Press, Madison, WI), pp61-164

[5] Nipponianippon(in Japanese)(1983), eds Yamashima Y, Nakanishi G(Newton Books, Tokyo).pp 301

[6] Su Y(2008) Conservation and management of the Asian Crested ibis in China. J Disaster Res3:216-225

[7] Li X, Li D(1998) Current state and the future of the Crested ibis(Nipponianippon): Acasestudy bypopulationviability analysis. Ecol Res 13:323-333

[8] Archibald G-W, Lantis S-H, Lantis L-R, Munechika I(1980) Endangered ibis(Threskiornithinea): their future in the wild and in captivity. International Zoology Yearbook20:6-17

[9] Li X, Tian H, Li D(2009) Why the crested ibis declined in the middle twentieth century. Biodivers Conserv18:2165-2172

[10] Shi D-C, Cao Y-H(1994) The Crested ibis of China. China Forestry Publishing House
[11] Archibald G-W, Lantis S-H(1981) Japanese Crested Ibis -Nipponianippon The present status /Rare birds of the Far East.(Vladivostok) 37-46

[12] Park H-C, Cha J-S, Kim T-J(2009) Restoration of Crested ibis in Upo, Korea. The 64th annual meeting of the Korean association of biological sciences, programs and abstracts, Daejeon Univ.pp 53

[13] King C-E(1992) Breeding the Oriental white stork, Ciconiaboyciana, at VogelparkWalsrode, Germany. ZoolGart(NF) 62:339-350

[14] Murata K, Hasegawa T, Matsushima K(1993) The cause of death of Eastern white stork(Ciconiaciconiaboyciana) in captivity. J JpnAssocZool Aqua 34:23-27

[15] Itoh Y, Ogawa A, Murata K, Hosoda T, Mizuno S(1997) Identification of the sex of Oriental white stork, Ciconiaboyciana, by the polymerase chain reaction based on its sex chromosome-specific DNA sequence. Genes Genet Syst 72:51-56

[16] Khaledi K-J, Panandam J-M, Maheran A-A, Siraj S-S(2009) Reliable and fast molecular sexing in Bosindicus cattle using amelogenin gene primers. J ApplAnim Res 35:83-85

[17] Svensson E-M, Götherström A, Vretemark M(2008) A DNA test for sex identification in cattle confirms osteometric result. J ArchaeolSci 35:942-946

[18] Kikuchi M, Ishii S(2002) Sex idenntification of the Japanese Crested Ibis, Nipponianippon, by chromodomain helicase DNA binding protein(CHD) gene analysis. J Yamashina InstOrnithol 33:189-197

[19] Kim K-A, Cha J-S, Kim T-J, Kim K-M, Park H-C(2011) Sex identification of the first incubated chicks of the Crested Ibis Nipponianipponin Korea. J Life Sci 21:626-630

[20] Li M, Ding C, Wei F, Meng S, Xi Y, Lu B(2001) Sex-related gene and sex identification of Crested Ibis Nipponianippon(Ciconiiformes: Threskiornithidae). Chin Sci Bull46:6 69-671

[21] Griffiths R, Double M, Orr K, Dawson R(1998) A DNA test to sex most birds. Mol Ecol7:1071-1075

[22] Dubiec A, Zagalska M(2006) Molecular techniques for sex identification in birds. Biological Lett 43:3-12 